\title{
Effect of Triple Antibiotic Paste on The Bond Strength of Epoxy and Methacrylate Resin-Based Sealers to Root Canal Dentine
}

\section{Fereshte Sobhnamayan}

Shiraz University of Medical Sciences

Alireza Adl ( $\square$ adla@sums.ac.ir)

Shiraz University of Medical Sciences

Mahdi Sedigh-Shams

Shiraz University of Medical Sciences

Hossein Mirkhaghani

Shiraz University of Medical Sciences

\section{Research Article}

Keywords: Dentine, Epoxy, methacrylate, Push Bond strength, Resin, Sealer, Triple antibiotic paste

Posted Date: February 15th, 2021

DOl: https://doi.org/10.21203/rs.3.rs-192980/v1

License: (a) (i) This work is licensed under a Creative Commons Attribution 4.0 International License. Read Full License 


\section{Abstract}

Background: Triple antibiotic pastes (TAP) has gained popularity as a root canal medicament in regenerative endodontic procedures and other endodontic treatment modalities. As this medicament changes the chemical structure of dentine, it may affect the bond strength of endodontic sealers to radicular dentine. This study aimed to evaluate the effect of TAP on the bond Strength of epoxy and methacrylate resin- based sealers to root canal dentine.

Methods: In this in vitro study, eighty single-rooted human mandibular premolars were prepared using ProTaper rotary system. The specimens were randomly divided into a control group (without intracanal dressing) and an experimental group receiving TAP $(n=40)$. The intracanal dressing was removed after three weeks. Then samples of each group were randomly divided into four subgroups $(n=10)$ and obturated with gutta-percha and different resin-based sealers. G1: AH Plus, G2: Syntex, G3: EndoREZ, G4: MetaSEAL. After one week, 16 Slices of $1 \pm 0.1 \mathrm{~mm}$ thickness were obtained from the midroots of teeth in each subgroup and a push-out test was used to measure the bond strength. Slices were examined using a stereomicroscope at $30 \times$ to determine the mode of failure. The data were analyzed using two-way analysis of variance, one- way analysis of variance and Tukey post hoc tests $(a=0.05)$.

Results: Compared to control group, TAP significantly increased the bond strength of MetaSeal and EndoREZ ( $p<0.05)$. In the control group, epoxy resin- based sealers showed higher bond strength compared to methacrylate ones $(p=0.00)$. In TAP group, Syntex and EndoREZ showed significantly the greatest and the lowest bond strengths respectively $(p<.05)$. The analysis of failure modes revealed a predominance of mixed failures in all groups except for Syntex group in which most failures were cohesive.

Conclusions: TAP significantly increased the bond strength of methacrylate resin- based sealers.

\section{Background}

Even after meticulous chemomechanical preparation, complete eradication of microorganisms and their byproducts from the root canal system is impossible [1]. Therefore, application of intracanal medicaments has been suggested for further reduction of bacterial load [2, 3]. Calcium hydroxide $(\mathrm{CH})$ is the most commonly used intracanal medicament due to its antibacterial and anti-inflammatory effects, and ability to dissolve remnants of pulpal tissue [4]. However some deficits such as inability in the elimination of Enterococcus Faecalis [5] and being potentially toxic due to its high pH makes investigators to search for new therapeutic agents to be used as alternative intracanal medicaments [5]. Due to polymicrobial nature of endodontic infections a mixture of different antibiotics has also been proposed as potential intracanal medicaments [6].

Triple antibiotic paste (TAP), consisting of metronidazole, ciprofloxacin and minocycline, has been found to have excellent antimicrobial properties and to be biocompatible [7-11] .This medicament has been 
successfully used in treatment of infected teeth having large periradicular radiolucencies [6] and also in endodontic regeneration of immature necrotic teeth [12].

Despite of all favorable characteristic of TAP, similar to other intracanal medicaments, it cannot be completely cleaned from the root canal [13]. Moreover it has been showed that TAP changes the chemical structure of dentine [14].Therefore in teeth treated with this medicament, the bonding of endodontic sealers to radicular dentine may be affected. Nevertheless, Limited studies have been published concerning the impact of TAP on the bond strength of resin-based sealers to root dentine.

The only study that we could find in this regard was conducted by Ackay et a/ who showed that TAP enhanced the bond strength of AH plus, an epoxy resin-based sealer, to the root canal dentine [15]. However, this study suffers from the fact that only one endodontic sealer was evaluated. Moreover, to the best of our knowledge there are no data regarding the effect of pretreatment with TAP on the adherence of methacrylate resin-based sealers to the radicular dentine. Therefore, the aim of the present study was to evaluate and compare the effect of pretreatment with TAP on the bond strength of two epoxy resinbased (AH Plus, Syntex) and two methacrylate resin-based (EndoREZ, MetaSEAL) sealers.

\section{Methods}

The study was approved by the Ethics Committee of the Shiraz University of Medical Sciences (REC.1396.S94). All methods were carried out in accordance with relevant guidelines and regulations.

A sample of 80 human mandibular premolar teeth extracted for clinical reasons with the patients' informed consent were used in this study. A Buccolingual radiograph was taken for each tooth to ensure to the presence of a single canal. Exclusion criteria were open apices, resorptions, cracks, or previous root canal treatments.

The teeth were disinfected by immersion in $0.5 \%$ chloramines T solution for 48 hours and then kept in distilled water until use.

Each tooth was decoronated to obtain a standardized root length of $15 \mathrm{~mm}$. Working length was established by subtracting $1 \mathrm{~mm}$ from length of a size $10 \mathrm{~K}$-file that its tip was visible at the apical foramen. Cleaning and shaping were done using ProTaper rotary files (Dentsply Maillefer) up to size F4 (\# 40/0.06). Irrigation with $2 \mathrm{~mL}$ of $2.5 \%$ sodium hypochlorite (Chloraxid, Cerkamed, Poland) was performed before using each file.

At the end of preparation, each canal was rinsed with $5 \mathrm{~mL} 17 \%$ EDTA and $5 \mathrm{~mL} 1 \% \mathrm{NaOCl}$ each for one minute, and dried. At this stage the specimens were randomly allocated into a control group of no intracanal medicament $(n=40)$ and an experimental group receiving TAP as intracanal medicament $(n=$ 40). TAP was prepared by taking equal amounts of powdered metronidazole (Metromax, Tehran chemie, Tehran, Iran), ciprofloxacin (Ciproted, Tehran Darou Co., Tehran), and minocycline (Minocin, Watson 
Pharmaceuticals Inc., California, USA) and mixing them with sterilized distilled water in a powder/liquid ratio of 3:1.

Lentulo spirals no. 40 were used to transferred the prepared paste into the root canals. Then, the coronal openings were temporarily sealed with a cotton pellet and temporary restorative material (Cavisol, Golchai Co., Iran), and the samples were kept in an incubator at $37^{\circ} \mathrm{C}$ in $100 \%$ humidity for 21 days [16]. At the end of incubation period, TAP was removed by needle irrigation of canals with $10 \mathrm{~mL} 17 \%$ EDTA followed by $10 \mathrm{~mL} 2.5 \% \mathrm{NaOCl}$ [13] and a final flush of $5 \mathrm{~mL}$ distilled water. In the next step, the samples of both control group and experimental group were divided into four subgroups based on the sealers used for obturation of the root canals. Two epoxy resin-based sealers; G1: AH Plus (Dentsply DeTrey, Kontanz, Germany) and G2: Syntex (Cerkamed, Stalowa Wola, Poland), and two methacrylate resin-based sealers; G3: EndoREZ (Ultradent, SouthJordan, Utah, UAS) and G4: MetaSEAL (Parkell Inc, Edgewood, NY) were used.

Obturation in all groups was performed by a single cone technique with use of F4 gutta-percha cones combined with one of tested sealers. The F4 gutta-percha cones (Dentsply Maillefer, Ballaigues, Switzerland) were coated with respected sealers and inserted into the root canal up to the working length. The excess gutta-percha and sealer in the coronal portion were removed and in the methacrylate resinbased sealer groups $(G 3, G 4)$ the coronal surface was light cured for 40 seconds.

After that, the coronal openings were sealed with a temporary filling material, and the specimens were stored for one week at $37^{\circ} \mathrm{C}$ and $100 \%$ humidity to allow the sealers to set. Each root was then sectioned perpendicular to its long axis using a low speed saw (Mecatom T180; Presi SA, Angonnes, France) under continuous water irrigation. Two slices ( $1 \pm 0.1 \mathrm{~mm}$ thick) were obtained from the midroot of each tooth $(n=20)$. The slices were checked under a stereomicroscope and finaly 16 discs with round lumen were chosen from each subgroup.

A digital camera attached to a stereomicroscopic (Best Scope-3060c, China) was used to capture images from coronal and apical aspects of each slice under 32x magnification. Scope image software (Best Scope-3060c, China) was then used to measure the lumen diameters of both sides of the slices.

A universal testing machine (Zwick/Roell, Z050; Zwick/Roell, Ulm, Germany) was used for the push out bond strength test, at a crosshead speed of $1 \mathrm{~mm} / \mathrm{min}$ and with a $0.5-\mathrm{mm}$ diameter cylindrical plunge. Loading was performed in an apical-coronal direction until the displacement of the filling material. The maximum load before failure was recorded in newton and divided by the adhesion area, resulting in a bond strength expression in mega Pascal (MPa).

The adhesion area of the root canal filling was calculated using the following formula:

$\pi(R+r)\left[h^{2}+(R-r)^{2}\right]^{0.5}$, where $\pi$ is the constant $3.14, R$ is the radius of the coronal side, $r$ is the radius of the apical side, and $\mathrm{h}$ represents the thickness of the root slice [18]. 
After the test procedure, the specimens were observed under a stereomicroscope at $32 \times$ magnification to determine the mode of failure. Three types of failure were categorized: adhesive failure (at the sealerdentine interface), cohesive fracture (within the filing material or dentine), and mixed failure (a mixture of cohesive and adhesive failures)[19].

\section{Statistical analysis}

The data were analyzed using two-way analysis of variance. As there was a significant interaction effect between using TAP and the root canal sealers, one-way analysis of variance and post hock tucky's tests were used to detect the effect of the independent variables (using TAP and sealers) on the bond strength. All statistical analyses were done by using SPSS (version 20, SPSS Inc, Chicago, IL, USA) at a significance level of 0.05 .

\section{Results}

A significant interaction effect was found between sealer types and using TAP $(p<0.05)$.

The mean and standard deviation of the push-out bond strength values (MPa) of the sealers to the radicular dentine are indicated in Table 1.

Table 1: Mean \pm SD of push-out bond strength values.

\begin{tabular}{|llccc|}
\hline $\begin{array}{l}\text { Sealer } \\
\text { Medicament }\end{array}$ & AH Plus & Syntex & EndoREZ & MetaSEAL \\
\hline Control & $3.68 \pm 1.14^{\mathrm{aA}}$ & $3.86 \pm 2.54^{\mathrm{a}} A$ & $0.6 \pm 0.69^{\mathrm{bA}}$ & $0.96 \pm 0.82^{\mathrm{bA}}$ \\
\hline TAP & $3.92 \pm 1.04^{\mathrm{bA}}$ & $5.35 \pm 1.96_{\mathrm{a}} \mathrm{A}$ & $1.51 \pm 1.35^{\mathrm{CB}}$ & $3.79 \pm 1.05^{\mathrm{bB}}$ \\
\hline
\end{tabular}

The same lowercase letters (row) and uppercase letters (column) are not significantly different.

Compared to control group, TAP significantly increased the bond strength of methacrylate resin- based sealers ( $p=0.0001$ and $p=0.002$ for MetaSEAL and EndoREZ, respectively). In epoxy resin-based sealers (AH Plus and Syntex) the increase in the bond strength was not significant $(p>0.05)$.

In the control group, the epoxy resin-based sealers showed significantly higher bond strength compared to the methacrylate resin-based sealers $(p=0.0001)$. In the TAP group, the greatest and the lowest bond strengths were belonged to Syntex and EndoREZ respectively, which were significantly different from other sealers. $(p<.05)$.

The analysis of failure modes showed a predominance of mixed failure in all groups with the exception of Syntex group in which most failures were cohesive. 


\section{Discussion}

Adhesion of endodontic sealers to intraradicular dentine is an important property for two main reasons. In a static situation, it prevents the passage of fluids between the filing material and the radicular dentine [20]. In a dynamic situation, it minimizes the risk of dislodgment of root canal filing material during the restorative procedures or masticatory function [21,22]. Actually it has been reported that sealing ability and bond strength of endodontic sealers may strongly correlate with each other [23].

According to the result of the present study, TAP increased the bond strength of all tested resin-based sealers. However, the increase was statistically significant only for the methacrylate resin-based sealers.

Our findings are partly in accordance with those of Ackay et al [15] who evaluated the effects of $\mathrm{CH}$, TAP, and double antibiotic paste (DAP) on the bond strength of an epoxy resin-based sealer)to the radicular dentine. They reported higher bond strength in the TAP group, while DAP and $\mathrm{CH}$ did not show any promising effect. The authors [15] attributed their finding to the binding of residual minocycline to the calcium ions of dentinal walls via a chelation reaction. Although this theory may explain the incomplete removal of TAP from the root canals, we believe it does not clarify how the tested sealer bonded to the residual of TAP and in this way to the dentinal wall.

In our opinion, the increase of the bond strength of resin-based sealers to dentine after application of TAP could be attributed to the strong demineralizing and erosive effect of this medicament on radicular dentine due to its low $\mathrm{pH}$ value $[14,24,25]$. This erosive effect increases the adhesion surfaces, which in turn may improve the adhesion of sealers to dentine. More investigations are needed to confirm this theory.

On the other hand, in the study of Arsalan et al [26], TAP decreased the bond strength of a self-adhesive resin cement (RelyX U200; 3M ESPE, Seefeld, Germany) to the root dentine. As normally the acid groups of this cement chemically interact with calcium ions of hydroxyapatite crystals, the authors discussed that the bonding strength would be adversely affected because the calcium ions had been previously chelated by minocycline. The authors also mentioned that the incomplete removal of TAP from the canal walls could be another possible reason for decrease of bond strength. The discrepancy between the results of Arsalan study[26] and the present study could be attributed to the different types of material used (resin cement versus resin sealers) and also different protocols used for removal of TAP.

The result of the present study showed that in the control group, both epoxy resin- based sealers presented significantly higher bond strength than both of methacrylate resin-based sealers. This finding is in agreement with the result of previous studies comparing the bond strength of these two subgroups of resin-based sealers [27-29].The stronger adhesion of epoxy resin-based sealers has been attributed to the lower volumetric polymerization shrinkage and higher penetration to the dentinal tubules [30-32].

In the current study, Syntex showed the maximum bond strength both in control and in TAP groups. Its difference was even significant with $\mathrm{AH}$, another epoxy based sealer, in TAP group. Syntex is a new epoxy 
resin-based sealer that according to its manufacturer has minimal shrinkage upon setting, particles of the smallest possible size, and excellent penetration properties. These features can explain the good adhesion of this sealer found in the current study. In addition, evaluation of the root dicks after the pushout test demonstrated a predominance of cohesive failure for Syntex but mixed failure for other groups, which confirms the better adhesive performance of this new epoxy resin-based sealer.

\section{Conclusions}

Under the limitation of this in vitro study, it can be concluded that TAP improved the bond strength of the methacrylate resin-based sealers.

\section{Declarations}

-Ethics approval and consent to participate: This study design was approved by the Ethics in Human Research Committee of Shiraz University of Medical Sciences (Ethics ID no. IR.SUMS.DENTAL. REC.1396.S94)). All human extracted teeth used for this study collected from the Oral and Maxillofacial Surgery Department of Shiraz dental school. These patients informed that their tooth will be used for research purposes and all of the patients or their parents signed a written consent form before the extraction of teeth.

-Consent for publication: Not applicable.

-Availability of data and materials: The datasets used and/or analysed during the current study are available on the journal request.

-Competing interests: The authors of this article have no financial and non-financial competing interests.

-Funding: This study was funded by the Vic-Chancellery of Shiraz University of Medical Science (Grant\# 1894)

\section{-Authors' contributions:}

- Constructing the idea for the research: F. Sobhnamayan

- Planning methodology to reach the conclusion: F. Sobhnamayan, A. Adl, M. Sedigh-shams

- Organising and supervising the course of the project: F. Sobhnamayan

- Taking responsibility in execution of the experiments, data management and reporting: $\mathrm{F}$. Sobhnamayan, M. Sedigh-shams, H. Mirkhaghani

- Taking responsibility in logical interpretation and presentation of the results: F. Sobhnamayan, A. Adl, M. Sedigh-shams 
- Taking responsibility in the construction of the body of the manuscript: F. Sobhnamayan, A. Adl, M. Sedigh-shams, H. Mirkhaghani

- Reviewing the article before submission not only for spelling and grammar but also for its intellectual content: A. Adl

-Acknowledgements: The authors thank the Vic-Chancellery of Shiraz University of Medical Science for supporting this research (Grant\# 1894). The authors also thank Dr. Vossoughi from the Center for Research Improvement of the School of Dentistry for the statistical analysis.

-Corresponding author. Alireza Adl (email address: adla@sums.ac.ir)

\section{References}

1. Barbizam JVB, Fariniuk LF, Marchesan MA, Pecora JD, Sousa-Neto MD. Effectiveness of manual and rotary instrumentation techniques for cleaning flattened root canals. J Endod. 2002;28(5):365-366.

2. Estrela C, Holland R, Bernabé PFE, Souza Vd, Estrela CRA. Antimicrobial potential of medicaments used in healing process in dogs' teeth with apical periodontitis. Braz Dent J. 2004;15:181-185.

3. Athanassiadis B, Abbott P, Walsh LJ. The use of calcium hydroxide, antibiotics and biocides as antimicrobial medicaments in endodontics. Aust Dent J. 2007;52(s1).

4. Byström A, Claesson R, Sundqvist G. The antibacterial effect of camphorated paramonochlorophenol, camphorated phenol and calcium hydroxide in the treatment of infected root canals. Dent Traumatol. 1985;1(5):170-175.

5. Siqueira JF, Jr., Lopes HP. Mechanisms of antimicrobial activity of calcium hydroxide: a critical review. Int Endod J. 1999;32(5):361-369.

6. Taneja S, Kumari M. Use of triple antibiotic paste in the treatment of large periradicular lesions. $J$ Investig Clin. Dent. 2012;3(1):72-76.

7. Sato I, Ando-Kurihara N, Kota K, Iwaku M, Hoshino E. Sterilization of infected root-canal dentine by topical application of a mixture of ciprofloxacin, metronidazole and minocycline in situ. Int Endod J. 1996;29(2):118-124.

8. Hoshino E, Kurihara-Ando N, Sato I, Uematsu H, Sato M, Kota K, et al. In-vitro antibacterial susceptibility of bacteria taken from infected root dentine to a mixture of ciprofloxacin, metronidazole and minocycline. Int Endod J. 1996;29(2):125-130.

9. Thibodeau B, Teixeira F, Yamauchi M, Caplan DJ, Trope M. Pulp revascularization of immature dog teeth with apical periodontitis. J Endod. 2007;33(6):680-689.

10. Gomes-Filho JE, Duarte PCT, de Oliveira CB, Watanabe S, Lodi CS, Cintra LTÂ, et al. Tissue reaction to a triantibiotic paste used for endodontic tissue self-regeneration of nonvital immature permanent teeth. J Endod. 2012;38(1):91-94. 
11. Windley W, Teixeira F, Levin L, Sigurdsson A, Trope M. Disinfection of immature teeth with a triple antibiotic paste. J Endod 2005;31:439-43.

12. Diogenes A, Henry MA, Teixeira FB, Hargreaves KM. An update on clinical regenerative endodontics. Endod Topics 2013;28(1):2-23.

13. Arslan H, Capar I, Saygili G, Uysal B, Gok T, Ertas H, et al. Efficacy of various irrigation protocols on the removal of triple antibiotic paste. Int Endod J. 2014;47(6):594-599.

14. Yassen GH, Chu T-MG, Eckert G, Platt JA. Effect of medicaments used in endodontic regeneration technique on the chemical structure of human immature radicular dentin: an in vitro study. $J$ Endod. 2013;39(2):269-273.

15. Akcay M, Arslan H, Topcuoglu HS, Tuncay O. Effect of calcium hydroxide and double and triple antibiotic pastes on the bond strength of epoxy resin-based sealer to root canal dentin. J Endod. 2014;40(10):1663-1667.

16. Carmen L, Asunción M, Beatriz S, Rosa Y-V. Revascularization in immature permanent teeth with necrotic pulp and apical pathology: case series. Case Rep Dent. 2017;2017.

17. Amin SAW, Seyam RS, El-Samman MA. The effect of prior calcium hydroxide intracanal placement on the bond strength of two calcium silicate-based and an epoxy resin-based endodontic sealer. $J$ Endod. 2012;38(5):696-699.

18. Prado M, Simão RA, Gomes BP. Effect of different irrigation protocols on resin sealer bond strength to dentin. J Endod. 2013;39(5):689-692.

19. Nagas E, Uyanik MO, Eymirli A, Cehreli ZC, Vallittu PK, Lassila LV, et al. Dentin moisture conditions affect the adhesion of root canal sealers. J Endod. 2012;38(2):240-244.

20. Ørstavik D, Eriksen H, BEYER-OLSEN EM. Adhesive properties and leakage of root canal sealers in vitro. Int Endod J. 1983;16(2):59-63.

21. Stewart GG. A comparative study of three root canal sealing agents. Oral Surg Oral Med Oral Pathol Oral Radiol Endod 1958;11(9):1029-1041.

22. Gurgel-Filho ED, Leite FM, Lima JBd, Montenegro JPC, Saavedra F, Silva EJNL. Comparative evaluation of push-out bond strength of a MTA-based root canal sealer. "Braz J Oral Sci 2014;13(2):114-117.

23. Neelakantan P, Subbarao C, Subbarao C, De-Deus G, Zehnder M. The impact of root dentine conditioning on sealing ability and push-out bond strength of an epoxy resin root canal sealer. Int Endod J. 2011;44(6):491-498.

24. Gündoğar M. Impact of intracanal calcium hydroxide or triple antibiotic paste on bond strength of root canal sealers: an in vitro study. Cumhuriyet Dent J 2016;19(3):229-237.

25. Sun Y, Li Y-h, Fan M-w. Push-out bond strength of self-adhesive methacrylate resin-based sealers to root dentin. J HUAZHONG U SCI-MED 2014;34(1):108-113.

26. Arslan H, Akcay M, Çakir M, Gok A, Yasa B, Dalli M. Comparison of bond strength of self-etch adhesive to pulp chamber dentin after placement of calcium hydroxide and various antibiotic pastes. 
Acta Odontol Scand. 2015;73(3):226-231.

27. Patil SA, Dodwad PK, Patil AA. An in vitro comparison of bond strengths of Gutta-percha/AH Plus, Resilon/Epiphany self-etch and EndoREZ obturation system to intraradicular dentin using a push-out test design. J Conserv Dent. 2013;16(3):238.

28. Vilanova W, Carvalho-Junior J, Alfredo E, Sousa-Neto M, Silva-Sousa Y. Effect of intracanal irrigants on the bond strength of epoxy resin-based and methacrylate resin-based sealers to root canal walls. Int Endod J. 2012;45(1):42-48.

29. Jainaen A, Palamara J, Messer H. Push-out bond strengths of the dentine-sealer interface with and without a main cone. Int Endod J. 2007;40(11):882-890.

30. De-Deus G, Di Giorgi K, Fidel S, Fidel RAS, Paciornik S. Push-out bond strength of Resilon/Epiphany and Resilon/Epiphany self-etch to root dentin. J Endod. 2009;35(7):1048-1050.

31. Ørstavik D, Nordahl I, Tibballs JE. Dimensional change following setting of root canal sealer materials. Dent Mater. 2001;17(6):512-519.

32. Souza S, Bombana A, Francci C, Goncalves F, Castellan C, Braga R. Polymerization stress, flow and dentine bond strength of two resin-based root canal sealers. Int Endod J. 2009;42(10):867-873. 